\title{
Hyperspectral Remote Sensing of Vegetation Using Red Edge Position Techniques
}

\author{
${ }^{1}$ Helmi Zulhaidi Mohd Shafri, ${ }^{2}$ Mohamad Amran Mohd Salleh and ${ }^{1}$ Azadeh Ghiyamat \\ ${ }^{1}$ Geomatics Eng. Unit, Dep. of Civil Eng., Universiti Putra Malaysia (UPM), 43400 Serdang, Selangor, Malaysia \\ ${ }^{2}$ Material Science Eng. Unit, Dep. of Chemical and Environmental Eng., UPM, 43400 Serdang, Selangor, Malaysia
}

\begin{abstract}
Two red edge position (REP) techniques, Linear and Lagrangian, were applied on hyperspectral data acquired from the HyMap sensor for a forested area in Thetford Forest, UK. Red edge positions of different vegetation covers were extracted with the two approaches from the hyperspectral data. Based on the estimated REPs, the Linear and Lagrangian interpolation methods were compared with ground reference image to analyse different vegetation types and ages. Experimental results of both interpolation techniques indicate that the wavelength and reflectance of REP for younger plants (higher chlorophyll content) shift towards longer wavelength and of higher reflectance in comparison with older plants (lower chlorophyll content).
\end{abstract}

Key words: Hyperspectral, Linear, Lagrangian, chlorophyll, red edge position

\section{INTRODUCTION}

Approximately, 70 percent of the Earth's land surface is covered with vegetation ${ }^{[1]}$. Furthermore, vegetation provides a basic foundation for all living beings and it is one of the most important components of the ecosystem ${ }^{[1-2]}$. Knowledge about variations in vegetation species and community distribution patterns, alterations in vegetation phenological (growth) cycles, and modifications in the plant physiology and morphology provide valuable insight into the climatic, edaphic, geologic, and physiographic characteristics of an $\operatorname{are}^{[3]}$.

Scientists are concerned with observing nature, making careful observations and measurements, and then attempting to accept or reject hypotheses concerning these phenomena ${ }^{[1]}$. As direct data measurement and collection is labor intensive and time consuming ${ }^{[4]}$, it is also possible to collect information about an object or geographic area from a distant vantage point using specialized instruments (sensors).

Scientists have devoted a significant amount of effort to develop sensors and visual and digital image processing algorithms to extract important vegetation biophysical information from remotely sensed data ${ }^{[5-6]}$. Hyperspectral remote sensor data can provide a significant enhancement of spectral measurement capabilities over conventional remote sensor systems that can be useful for the identification and subsequent modeling of terrestrial ecosystem characteristics ${ }^{[7-8]}$. Hyperspectral data also can provide significant improvements in spectral information content when compared with broadbands for detecting plant $\operatorname{stress}^{[9-}$ ${ }^{10]}$, measuring chlorophyll content of plants ${ }^{[11]}$, identifying small differences in percent green vegetation cover ${ }^{[12]}$, extracting biochemical variables such as nitrogen and lignin ${ }^{[13]}$, discriminating land cover (LC) types $^{[14]}$, crop moisture variations ${ }^{[15-16]}$, leaf pigment concentrations $^{[11]}$, modeling quantitative biophysical and yield characteristics of agricultural crops ${ }^{[17]}$, improving detection change in sparse vegetation ${ }^{[18-19]}$ and assessing absolute water content in plant leaves ${ }^{[20]}$.

Currently, a variety of techniques have been used for the detection of early-stage vegetation stress in airborne and satellite imagery. These techniques include a number of different vegetation indices (VI), "rededge" detection, band absorption analysis, spectral mixture analysis, wavelet transform and neural networks ${ }^{[21]}$. Red edge parameters, compared with VIs, are relatively insensitive to changes of biophysical factors, such as soil cover percentage and optical properties $^{[22-24]}$, canopy structure and leaf optical properties $^{[22,25]}$, atmospheric effects ${ }^{[26]}$ and irradiance and solar zenith angle ${ }^{[22,25]}$.

The red edge is the name given to the abrupt reflectance change in the 680-740 $\mathrm{nm}$ region of vegetation spectra that is caused by the combined effects of strong chlorophyll absorption and leaf internal scattering $^{[27]}$. Experimental and theoretical studies show that REP shifts according to changes of chlorophyll content $^{[28-29]}$, LAI $^{[30]}$, biomass and hydric status ${ }^{[31]}$, age $^{[32]}$, plant health levels ${ }^{[33]}$, and seasonal patterns ${ }^{[34]}$. When a plant is healthy with high chlorophyll content and high LAI, the red edge position shifts toward the longer wavelengths; when it suffers from disease or chlorosis and low LAI, it shifts toward the shorter wavelengths ${ }^{[4]}$. These observations on REP can effectively be used to classify and distinguish different vegetation types and ages in this study.

To investigate the use of REP as a mean to classify vegetation, various techniques of analysis such as, four point interpolation (Linear), Gaussian, Lagrangian,

Corresponding Author: Department of Civil Engineering, Universiti Putra Malaysia (UPM), 43400 Serdang, Selangor, MALAYSIA. Tel: 03-89466459, Fax:03-86567129 
polynomial fitting and high order curve fitting techniques have been developed to minimize errors in determining the red edge position ${ }^{[4,27]}$. Through these techniques, the Gaussian and high order curve fitting techniques are more complex in implementation than the Linear and Lagrangian techniques ${ }^{[27]}$. The Linear approach is computationally simple, robust, the most practical and suitable method for extracting the REP from hyperspectral data rather than other methods because only four bands and a simple interpolation computation are needed ${ }^{[35]}$. On the other hand, the Lagrangian interpolation which is based on derivative analysis, estimates REP by using wavebands with no equal-space requirement, minimizes interpolation errors and soil background effects and computationally, it is one of the simpler curve fitting techniques ${ }^{[36]}$. Based on these advantages of the two Linear and Lagrangian methods, recently many applications have been considered to these methods for estimating $\operatorname{REP}^{[4,27,37-}$ ${ }^{44]}$. Therefore, in this analysis the objective is to study the performance of Linear and Lagrangian approaches for extracting the REP from HyMap data for estimating different vegetation covers (types and ages), to compare the two methods in detecting REP and to assess the ability of hyperspectral remote sensing data to estimate different vegetation covers based on the Linear and Lagrangian REP.

\section{STUDY AREA AND DATA SETS}

Study area: The study area is located in the Thetford Forest of Breckland, East Anglia. It is Britain's largest lowland pine forest area and occupies an area of approximately 22,000 hectares. The forest area consists mainly of planted and managed Corsican and Scots pine of different age classes, and has a low relative relief. Corsican pine is the most profitable and suitable conifer for planting in much of lowland Britain particularly on light soils in the East of the country. It grows quickly and the combination of its straight trunks and light branches produces good timber with few knots. Corsican pine dominates Thetford Forest in East Anglia, which is the largest man-made pine forest in Britain. Timber from this pine is used in building, roofing, flooring and interior framing.

The native Scots pine is also common in Britain. Scots pine was planted as early as 1922 but has been slowly replaced with Corsican pine due to the latter's higher yield, better timber and greater resistance to disease. The Forestry Commission (UK) is the government agency responsible for the management and maintenance of British forests.

Hyperspectral data: The hyperspectral data used in this study was acquired from the HyMap sensor for a forested area in Thetford Forest, UK. The HyMap data was acquired on 17 June 2000 as part of the BNSCNERC SHAC airborne campaign. This campaign aims to support UK academic and industrial research and application developments ${ }^{[45]}$. The spatial resolution of the data is $5 \mathrm{~m}$. The spectral characteristics of the HyMap data are shown in Table 1. The HyMap sensor provides an excellent signal to noise ratio (>500:1) and image quality that is setting the industry standard ${ }^{[46]}$.

Table 1: The spectral characteristics of the HyMap sensor (Adapted from HyVista, 2002 ${ }^{[46]}$ )

\begin{tabular}{cccc}
\hline \multicolumn{3}{c}{ Spectral configuration } \\
\hline Module & Spectral range & $\begin{array}{c}\text { Bandwidth } \\
\text { across module }\end{array}$ & $\begin{array}{c}\text { Average spectral } \\
\text { sampling interval }\end{array}$ \\
VIS & $0.45-0.89 \mu \mathrm{m}$ & $15-16 \mathrm{~nm}$ & $15 \mathrm{~nm}$ \\
NIR & $0.89-1.35 \mu \mathrm{m}$ & $15-16 \mathrm{~nm}$ & $15 \mathrm{~nm}$ \\
SWIR1 & $1.40-1.80 \mu \mathrm{m}$ & $15-16 \mathrm{~nm}$ & $13 \mathrm{~nm}$ \\
SWIR2 & $1.95-2.48 \mu \mathrm{m}$ & $18-20 \mathrm{~nm}$ & $17 \mathrm{~nm}$ \\
\hline
\end{tabular}

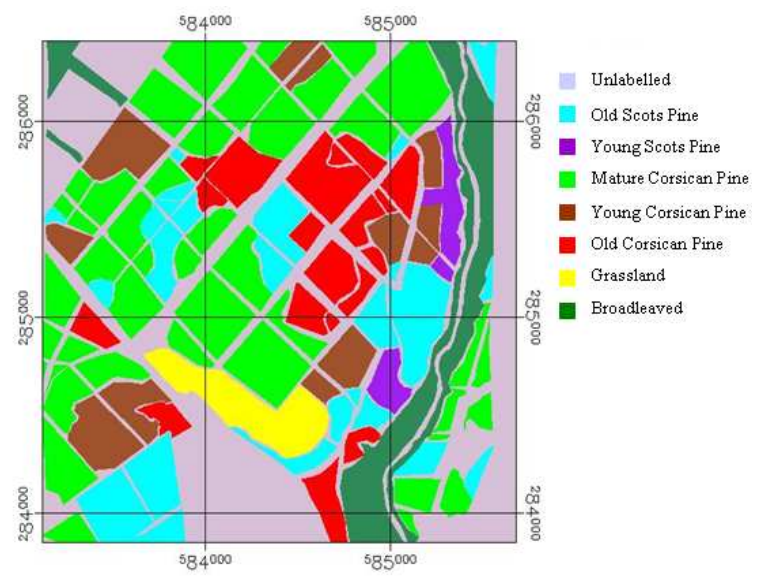

Fig. 1: Ground reference image of the study area

Ground reference data: The ground reference data are generated from the UK Forestry Commission's GIS vector data and stock map, which is a scanned image of the digitized and vectorised ground reference data, is presented in Fig. 1. There are several regions in the ground reference data, which include seven different vegetation covers such as old Scots pine (OCP), young Scots pine (YSP), mature Corsican pine (MCP), young Corsican pine (YCP), old Corsican pine (OCP), broadleaved (BL) and grassland (GL).

\section{MATERIALS AND METHODS}

Linear interpolation technique: Guyot and Baret $(1988)^{[37]}$ have applied a simple linear model to the red infrared slope. They used four wavelength bands, centered at 670,700, 740 and 780nm. Reflectance measurements at $670 \mathrm{~nm}$ and $780 \mathrm{~nm}$ are used to estimate the inflection point reflectance (Equation 1) and a linear interpolation procedure is applied between $700 \mathrm{~nm}$ and $740 \mathrm{~nm}$ to estimate the wavelength of the inflection point (Equation 2) ${ }^{[7]}$

$R_{\text {REP }}=\frac{R_{670}+R_{780}}{2}$ 
$\lambda_{R E P}=\lambda_{700}+\left(\lambda_{740}-\lambda_{700}\right) \times\left[\frac{R_{R E P}-R_{700}}{R_{740}-R_{700}}\right]$.

For calculating red edge position of each pixel, reflectance and wavelength of those bands, which have closest wavelength values to the 670, 700, 740 and 780 $\mathrm{nm}$, need to be extracted from the original image. Calculation of REP for the selected pixel based on Equations 1 and 2 are presented in the following, in which the reflectance at the inflection point $\left(R_{R E P}\right)$ is:

$R_{\text {REP }}=\frac{R_{670}+R_{780}}{2}=\frac{296+2089}{2}=1192.5$

and wavelength of red edge $\left(\lambda_{R E P}\right)$ corresponding to the estimated reflectance value at the inflection point is:

$$
\begin{aligned}
& \lambda_{R E P}=\lambda_{700}+\left(\lambda_{740}-\lambda_{700}\right) \times\left[\frac{R_{R E P}-R_{700}}{R_{740}-R_{700}}\right] \\
& \lambda_{R E P}=707.8+(738.1-707.8) \times\left[\frac{1192.5-706}{1677-706}\right]=722.9812
\end{aligned}
$$

(nm).

REP for the selected pixel which was calculated by using the Linear method is represented on its zoomed plot of spectral profile as shown in Fig. 2.

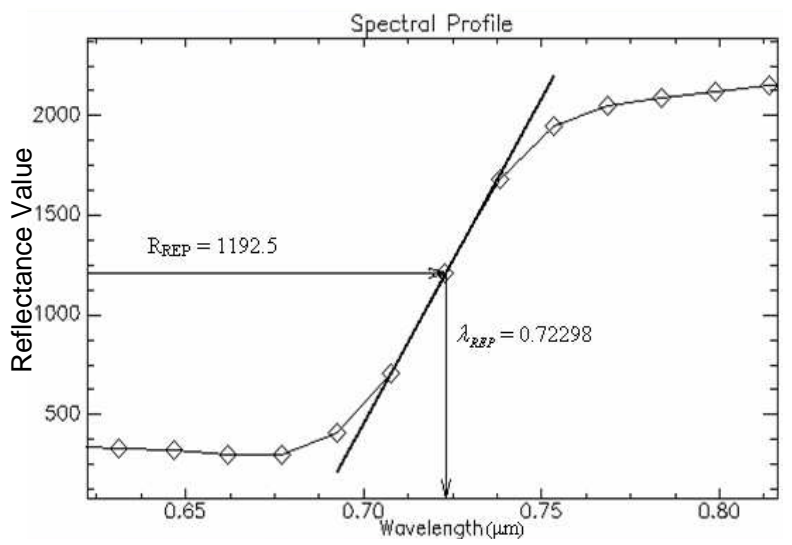

Fig. 2: REP for the selected pixel, which was calculated by using the Linear method

Lagrangian interpolation technique: Another technique for calculating REP in this study is the Lagrangian technique, which is based on spectrum derivative analysis, proposed by Dawson and Curran $(1998)^{[27]}$. The advantage of derivative spectroscopy is that it is relatively insensitive to variations in illumination intensity, which may be caused by changes in sun angle, cloud cover, topography and atmospheric attenuation $^{[43]}$. When such factors are removed, any differences observed are more likely to be due to leaf chemical composition, leaf structure or water content ${ }^{[47]}$. Secondly, derivative spectroscopy can enhance smaller peaks that are obscured by larger peaks due to noise ${ }^{[48]}$ and can be used to facilitate the location of key spectral features such as the red edge and chlorophyll peak reflectance $^{[49]}$.

The Lagrangian technique uses three points interpolation for estimating REP. A second order polynomial uses to fit the first derivative vegetation reflectance spectrum and reflectance in three wavebands, in which they are the bands with maximum first derivative reflectance and two adjoining bands. The derivative reflectance $\left(D R_{R E P}\right)$ and wavelength $\left(\lambda_{R E P}\right)$ of REP were calculated using equation (3) and (4) respectively, i.e.,

$$
\begin{aligned}
& D R_{R E P}=\frac{\left(\lambda-\lambda_{i}\right)\left(\lambda-\lambda_{i+1}\right)}{\left(\lambda_{i-1}-\lambda_{i}\right)\left(\lambda_{i-1}-\lambda_{i+1}\right)} D_{\lambda(i-1)}+\frac{\left(\lambda-\lambda_{i-1}\right)\left(\lambda-\lambda_{i+1}\right)}{\left(\lambda_{i}-\lambda_{i-1}\right)\left(\lambda_{i}-\lambda_{i+1}\right)} D_{\lambda(i)} \\
& +\frac{\left(\lambda-\lambda_{i-1}\right)\left(\lambda-\lambda_{i}\right)}{\left(\lambda_{i+1}-\lambda_{i-1}\right)\left(\lambda_{i+1}-\lambda_{i}\right)} D_{\lambda_{(i+1)}} \\
& \lambda_{R E P}=\frac{A\left(\lambda_{i}+\lambda_{i+1}\right)+B\left(\lambda_{i-1}+\lambda_{i+1}\right)+C\left(\lambda_{i-1}+\lambda_{i}\right)}{2(A+B+C)} \\
& \text { where } \\
& B=\frac{A=\frac{D_{\lambda_{(i-1)}}}{\left(\lambda_{i-1}-\lambda_{i}\right)\left(\lambda_{i-1}-\lambda_{i+1}\right)}}{\left(\lambda_{i}-\lambda_{i-1}\right)\left(\lambda_{i}-\lambda_{i+1}\right)} \text { and } \\
& C=\frac{D_{\lambda_{(i+1)}}}{\left(\lambda_{i+1}-\lambda_{i-1}\right)\left(\lambda_{i+1}-\lambda_{i}\right)}
\end{aligned}
$$

and where $D_{\lambda(i-1)}, D_{\lambda(i)}$ and $D_{\lambda(i+1)}$ are the first derivative reflectance values around the red edge position of the maximum slope at wavelengths $\lambda_{i-1}, \lambda_{i}$ and $\lambda_{i+1}$ respectively. In this study, for each pixel, wavelength and derivative reflectance of the maximum first derivative (band 20) and the two adjoining bands 19 and 21 are extracted from first derivative of original hyperspectral image. Then, the Lagrangian's equations applied to estimate red edge position of the selected pixel, are shown as the following:

$A=\frac{D_{\lambda(19)}}{\left(\lambda_{19}-\lambda_{20}\right)\left(\lambda_{19}-\lambda_{21}\right)}=\frac{3975}{(7078-7229)(7078-7381)}=0.868$

$$
\begin{aligned}
& B=\frac{D_{\lambda_{(20)}}}{\left(\lambda_{20}-\lambda_{19}\right)\left(\lambda_{20}-\lambda_{21}\right)}= \\
& \frac{485.5}{(7229-707.8)(7229-738.1)}=-2.1153 \text { and }
\end{aligned}
$$$$
C=\frac{D_{\lambda_{(21)}}}{\left(\lambda_{21}-\lambda_{19}\right)\left(\lambda_{21}-\lambda_{20}\right)}=
$$

$\frac{371}{(738.1-707.8)(738.1-722.9)}=0.8055$.

Based on Equation 4, the wavelength value of REP $\left(\lambda_{R E P}\right)$ is calculated as: 
$\lambda_{\text {REP }}=\frac{A\left(\lambda_{20}+\lambda_{21}\right)+B\left(\lambda_{19}+\lambda_{21}\right)+C\left(\lambda_{19}+\lambda_{20}\right)}{2(A+B+C)}$

$=[0.8688(722.9+738.1)-2.1153(707.8+738.1)+$

$0.8055(707.8+722.8)] /[2(0.8688-2.1153+0.8055)] \Rightarrow$

$\lambda_{\text {REP }}=721.9583(\mathrm{~nm})$

and derivative reflectance value of $\operatorname{REP}\left(D R_{R E P}\right)$ is calculated as:

$$
\begin{aligned}
& D R_{R E P}=\frac{\left(\lambda-\lambda_{20}\right)\left(\lambda-\lambda_{21}\right)}{\left(\lambda_{19}-\lambda_{20}\right)\left(\lambda_{19}-\lambda_{21}\right)} D_{\lambda(19)} \\
& +\frac{\left(\lambda-\lambda_{19}\right)\left(\lambda-\lambda_{21}\right)}{\left(\lambda_{20}-\lambda_{19}\right)\left(\lambda_{20}-\lambda_{21}\right)} D_{\lambda(20)} \\
& +\frac{\left(\lambda-\lambda_{19}\right)\left(\lambda-\lambda_{20}\right)}{\left(\lambda_{21}-\lambda_{19}\right)\left(\lambda_{21}-\lambda_{20}\right)} D_{\lambda(21)}
\end{aligned}
$$

$D R_{R E P}=\left[\left(\frac{(721.9583-7229)(721.9583-7381)}{(707.8-7229)(707.8-7381)}\right) \times 397.5\right]$

$+\left[\left(\frac{(721.9583-707.8)(721.9583-738.1)}{(722.9-707.8)(722.9-738.1)}\right) \times 485.5\right]$

$+\left[\left(\frac{(721.9583-707.8)(721.9583-722.9)}{(738.1-707.8)(738.1-722.9)}\right) \times 371\right]$

$=485.8910$.

The calculated REP based on the Lagrangian interpolation technique is shown in Fig. 3, in which the horizontal and vertical axes represent wavelength $(\mathrm{nm})$ and first derivative reflectance respectively. The Matlab software is used to create and plot the interpolation curve.

\section{RESULTS AND ANALYSIS}

Performance of the Linear interpolation method: For classifying different vegetation covers, 139 test pixels are extracted from the 7 different vegetation covers of the original hyperspectral data. The REPs of these pixels are calculated based on the Linear method as shown in Fig. 4.

The results based on the scatter plot of the REPs show that the two coniferous and broadleaved species can easily be distinguished from each other as shown in Fig. 4. REPs of the broadleaved shift towards the longer wavelength and higher reflectance than REPs of the coniferous species. Based on REPs of the GL species in the scatter plot, this species cannot be distinguished from the two other species easily. Also, based on the scatter plot, REPs of different ages of the coniferous species are much dispersed with different location, therefore it is difficult to classify them. The statistical analysis (mean) was used to check if it offers better results than the scatter plot for classifying the vegetation covers.

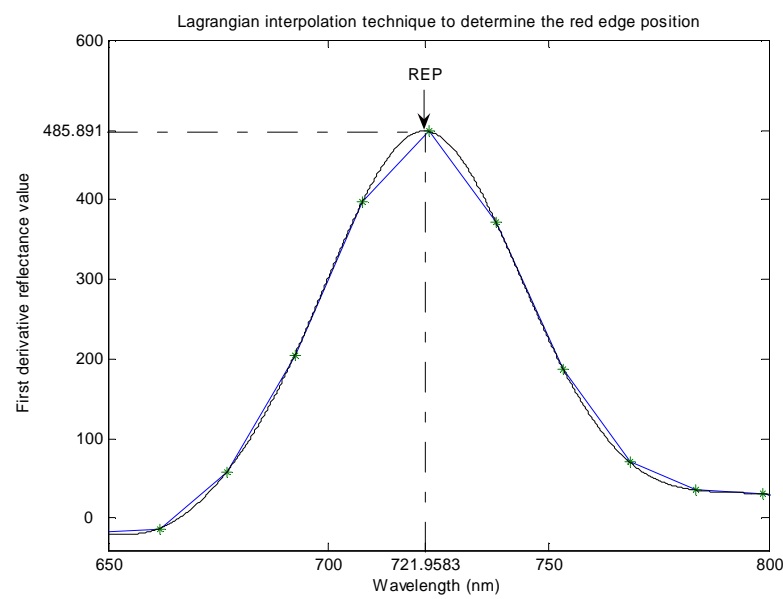

Fig. 3: The Lagrangian interpolation technique to estimate REP of the selected pixel

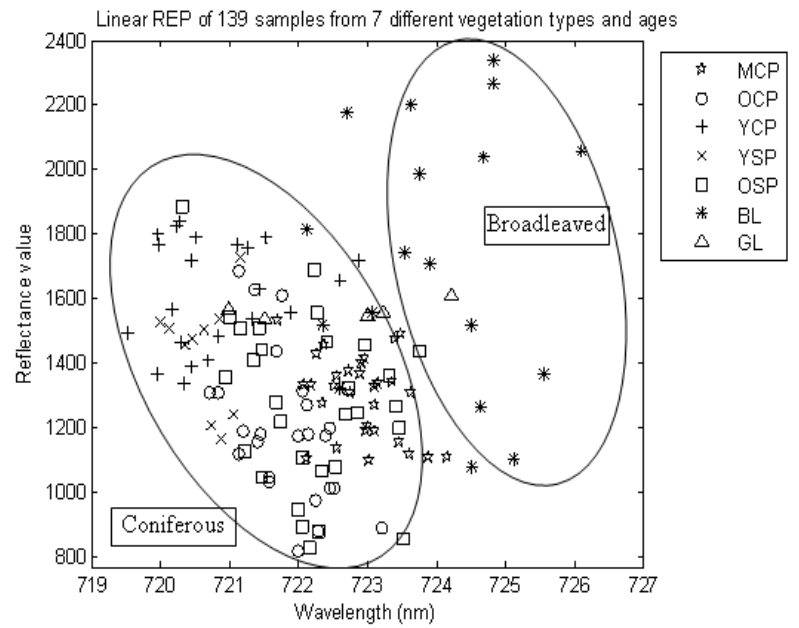

Fig. 4: Classifying vegetation species based on scatter plot of REP values for the Linear method

The results based on this simple statistical analysis confirm the results of the scatter plot for distinguishing between the coniferous and broadleaved species in which REP of the broadleaved species shifts towards longer wavelength and also has higher reflectance value than REPs of the coniferous species. The statistical analysis in Fig. 5 shows that distinguishing between grassland and broadleaved can also be done easily as REP of the broadleaved has longer wavelength and higher reflectance than REP of the grassland. But this classification parameters cannot easily be used to distinguish between grassland and coniferous.

For classifying the coniferous species based on their age, in this study they are classified into three groups of ages as young, mature and old. For classifying ages of plants, the theoretical study shows that, when plants have higher chlorophyll content and LAI (young), the REP shifts toward the longer wavelengths; when plants have low chlorophyll content and LAI (old), the REP shifts toward the shorter wavelengths ${ }^{[4]}$. The results based on the statistical analysis as shown in Fig. 5 is corresponding to the theoretical results in 
which REP of the older coniferous has shorter wavelength than REP of the mature coniferous. It is expected that, REP of the young coniferous shifts toward the longer wavelength than REP of the both mature and old coniferous. But based on the ground reference information, this is expected, because the young Corsican and Scots pines in this forest were very young and they should not have chlorophyll as much as a mature pine should have.

Performance of the Lagrangian interpolation technique: The same pixel coordinates of those 139 test pixels that are used for the Linear method are used for the Lagrangian method too. So that, these pixel coordinates are applied on the first derivative hyperspectral image for extracting the required information based on the Lagrangian's equations. The calculated REPs of the 139 test pixels are shown in Fig. 6.

The results based on the scatter plot of the REPs show that the two coniferous and broadleaved species can easily be distinguished from each other. As the polygons in the Fig. 6 shows, REPs of the broadleaved shift towards the longer wavelength and higher derivative reflectance than REPs of the coniferous species. Also, the broadleaved and grassland species can be distinguished from their REPs which REPs of the broadleaved shifts toward the longer wavelength and higher derivative reflectance than REPs of the grassland. But, the grassland species cannot be distinguished from the coniferous species easily. Also, based on the scatter plot, REPs of different ages of the coniferous species are much dispersed with different location and difficult to be classified. The statistical analysis (mean) was used to check if it offers better results than the scatter plot for classifying the vegetation covers.

The results based on this simple statistical analysis (Fig. 7), confirm the results of the scatter plot, for distinguishing between the coniferous and broadleaved species. The REP of the broadleaved species shifts towards longer wavelength and also has higher derivative reflectance value than REPs of the coniferous species. Also, the statistical analysis results are corresponding to the scatter plot for distinguishing between the grassland and broadleaved in which REP of the broadleaved has longer wavelength and higher derivative reflectance than REP of the grassland. In addition, the statistical analysis results that the grassland may be distinguished from the coniferous by considering the derivative reflectance value of their REP, but it can not be distinguished based on the wavelength of REP easily.

The results based on the statistical analysis shown in Fig. 7 is corresponding to the theoretical results in which REP of the older coniferous has shorter wavelength than REP of the mature coniferous. It is expected that REP of the young coniferous shifts toward the longer wavelength than REP of the both mature and old coniferous.

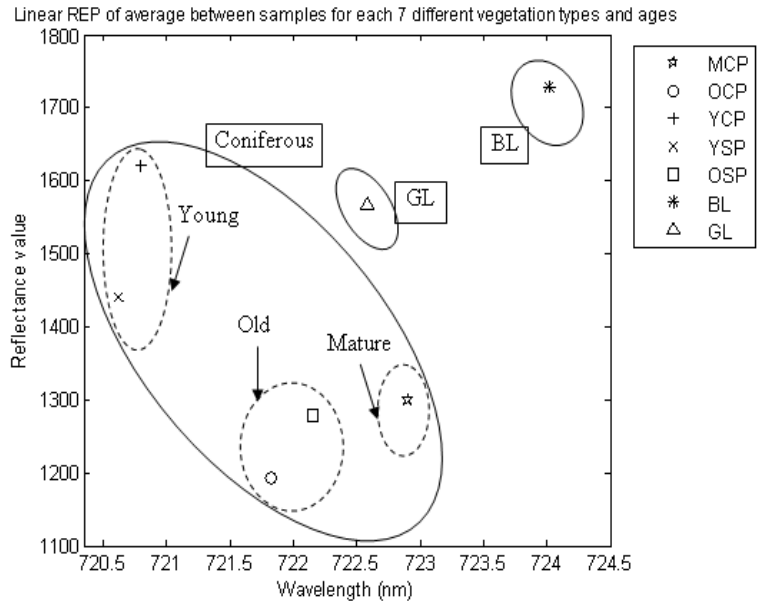

Fig. 5: Classifying different vegetation based on mean REP values for the Linear method

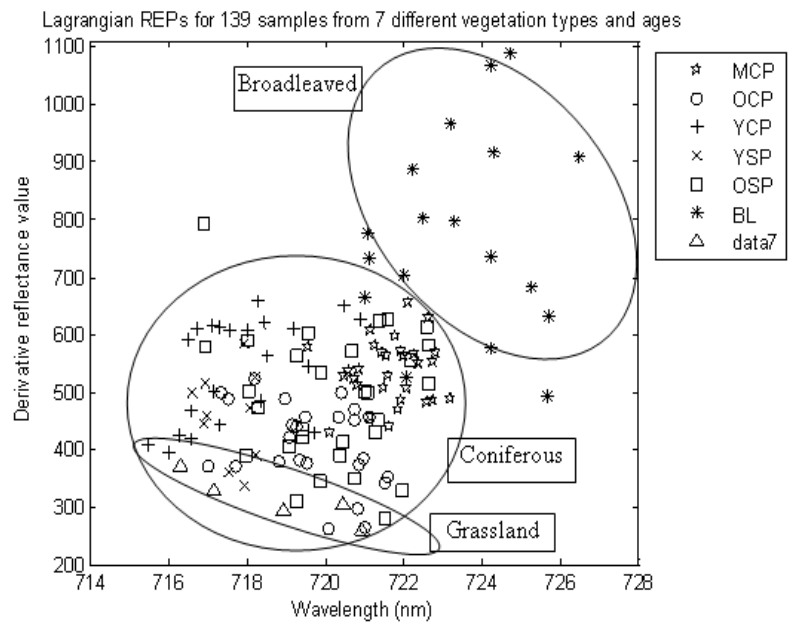

Fig. 6: Classifying vegetation species based on scatter plot of REP values for the Lagrangian method

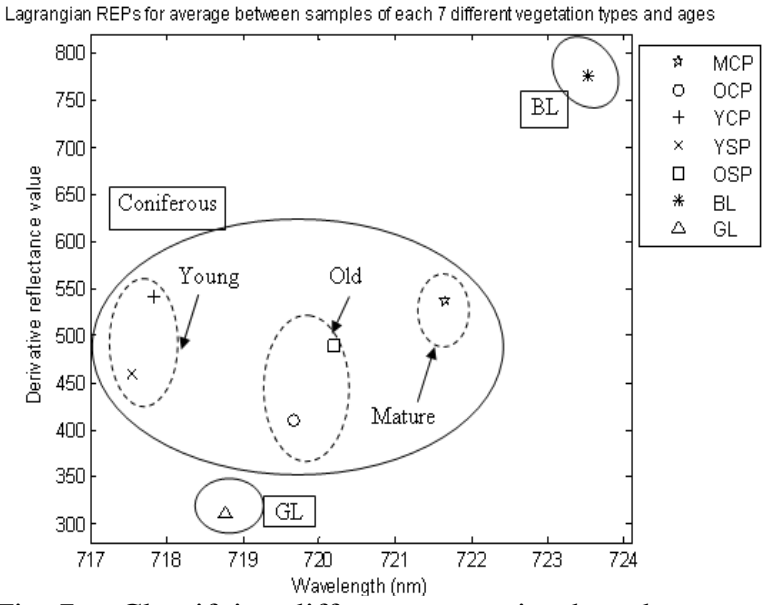

Fig. 7: Classifying different vegetation based on mean REP values for the Lagrangian method 
Am. J. Appl. Sci3 (6): 1864-1871, 2006

Table 2: A summary of the advantages and attributes of the two interpolation techniques for determining the REP

\begin{tabular}{lccccc}
\hline Methods & Implementation & $\begin{array}{c}\text { Required spectral } \\
\text { type }\end{array}$ & $\begin{array}{c}\text { Suitability for canopy } \\
\text { spectra }\end{array}$ & Red edge detection & $\begin{array}{c}\text { Minimizing soil background } \\
\text { effects }\end{array}$ \\
\hline Linear & Easy & Reflectance & Yes & Good & Low \\
Lagrangian & Moderate & Derivative & Yes & Good & High \\
\hline
\end{tabular}

Comparison of the Linear and Lagrangian interpolation techniques: For having a better comparison between the two methods to estimate REP, the mean values of the REPs for the two methods are represented together in Fig. 8. It shows that, there is similarity between the both methods for estimating the REPs of different vegetation covers, which wavelength of the young, old and mature coniferous and broadleaved species are distributed from the shorter to longer wavelength in both methods respectively. Based on the statistical analysis results, both the Lagrangian and Linear methods generate similar results for estimating REP of the coniferous and broadleaved species and different results for estimating REP of the grassland.

As the REP of the grassland in the Lagrangian method goes towards shorter wavelength and lower reflectance than the Linear method, it can be concluded that the Lagrangian approach offers more accurate results than the Linear method in estimating grassland, because the derivative approaches (Lagrangian technique) minimizes the soil background reflectance effects ${ }^{[27,50-55]}$. In classifying different ages of coniferous species, both methods offer the same results in extracting REP for different ages of coniferous species.

A summary of the attributes of the two methods is presented in Table 2. The differences between these two methods based on the computation are that the Linear method can be done easily as it only requires four bands. Implementation of the Lagrangian technique needs more computation time and if the first derivative spectra are available, we can simply take three bands containing the maximum first derivative reflectance value to determine REP. However, if the first derivative spectra are not available (for example, multispectral remote sensing data with very small number of bands), this method cannot be used.

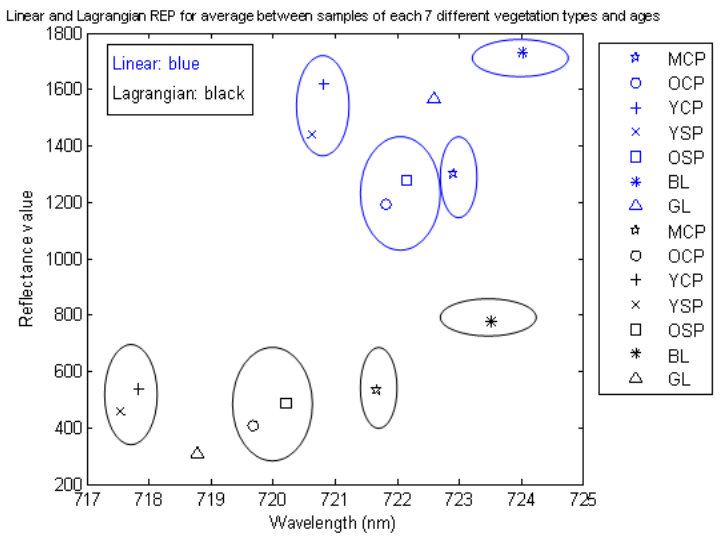

Fig. 8: Comparison of the mean REP values of the Linear and Lagrangian methods

\section{CONCLUSION}

139 test pixels from the HyMap were selected to extract REP using the two Linear and Lagrangian approaches for the goal of classifying vegetation species. The statistical analysis is applied to calculate the mean value of the REP for both methods. The statistical results show that, both the Linear and Lagrangian approaches generated similar results in extracting REP for the coniferous and the broadleaved species. They also offer similar results in estimating REP of different ages of coniferous species. But there are some differences between the two approaches in estimating REP of the grassland in which the Lagrangian technique generate more accurate results than the Linear method because of its less sensitivity to the soil background reflectance effects.

Comparison of the ground reference map and the REP of the test data suggested some degree of success in discriminating the broadleaved and coniferous trees. Based on the statistical results of both the Linear and Lagrangian methods, the broadleaved trees can be distinguished from the coniferous tress by considering their REP, in which REP of the broadleaved trees shift toward the longer wavelength and of higher reflectance than REP of the coniferous trees. Another successful result which had been obtained by comparison with the ground reference image is that different ages of the coniferous trees can be distinguished easily by considering the wavelength of their REP. The REP of the younger trees shift towards longer wavelength and REP of the older trees shift towards the shorter wavelength. The above results demonstrate the potential application of hyperspectral remote sensing and red edge position analysis for detecting different vegetation types and ages in a forested area.

\section{ACKNOWLEDGMENT}

We would like to thank Universiti Putra Malaysia (UPM) for the financial support in completing this research.

\section{REFERENCES}

1. Jensen, J.R, 2000. Remote sensing of the environment: an earth resource perspective. Prentice Hall series in geographic information science, USA, Chap. 1 and 10, pp: 1-28 and 333-377. 
2. Williams, J. A. 1992. Vegetation Classification Using Landsat TM and SPOT-HRV Imagery in Mountainous Terrain, Kananaskis Country, S. W. Alberta. Alberta Recreation and Parks, Kananaskis Country Operations Branch, Environmental Management, Canmore, Alberta.

3. Jones, K. B., K. H. Ritters, J. D. Wickham, R. D. Tankersley, R. V. O’Neill, D. J. Chaloud, E. R. Smith and A. C. Neale, 1998. An Ecological assessment of the United States: Mid-Atlantic Region, Washington: EPA., pp: 103.

4. Pu, R., P. Gong, G. Biging, and M. R. Larrieu, 2003. Extraction of Red Edge Optical Parameters from Hyperion Data for Estimation of Forest Leaf Area Index. IEEE Transactions on geoscience and remote sensing., 41 (4): 916-921.

5. Frohn, R. C. 1998. Remote Sensing for Landscape Ecology, Boca Raton, FL: Lewis Publishers., pp: 99.

6. Huete, A. and C. Justice, 1999. MODIS Vegetation Index (MOD 13) Algorithm Theoretical Basis Document, Greenbelt: NASA Goddard Space Flight Center.,http://modarch.gsfc.nasa.gav/MODIS/LAND/ \#vegetation-indices, pp: 129.

7. Kumar, L., K. S. Schmidt, S. Dury and A. K. Skidmore, 2001. Imaging Spectrometry and Vegetation Science. In F. van de Meer. and S.M. de Jong (Eds). Imaging Spectrometry (Kluwer Academic Press: Dordrecht)., pp: 111-155.

8. Thenkabail, P. S., E. A. Enclona, M. S. Ashton, and B. Van Der Meer, 2004. Accuracy Assessments of Hyperspectral Waveband Performance for Vegetation Analysis Applications. Remote Sensing of Environment., 91: 354-376.

9. Carter, G. A. 1994. Ratios of leaf reflectances in narrow wavebands as indicators of plant stress. International Journal of Remote Sensing., 15: 697-703.

10. Carter, G. A. 1998. Reflectance Bands and Indices for Remote Estimation of Photosynthesis and Stomatal Conductance in Pine Canopies. Remote Sensing of Environment., 63: 61-72.

11. Blackburn, G. A. and C. M. Steele, 1999. Towards the Remote Sensing of Matorral Vegetation Physiology: Relationships between Spectral Reflectance, Pigment, and Biophysical Characteristics of Semiarid Bushland Canopies. Remote Sens. of Environ., 70: 278-292.

12. McGwire, K., T .Minor, and L. Fenstermaker, 1999. Hyperspectral Mixture Modeling for Quantifying Sparse Vegetation Cover in Arid environments. Remote Sensing of Environment., 72 (3): 360-374.

13. Curran, P. J. 1994. Imaging spectrometry. Progress in Physical Geography., 18 (2): 247-266.

14. Janetos, A. C. and C. O. Justice, 2000. Land cover and global productivity: A measurement strategy for the NASA programme. International Journal of Remote Sensing., 21(6): 1491-1512.

15. Penuelas, J., I. Filella, C. Biel, L. Serrano, and R. Save, 1993. The reflectance at the 950-970 region as an indicator of plant water status. International Journal of Remote Sensing., 14 (10): 1887-1905.
16. Penuelas, J., I. Filella, , P. Lloret, , F. Munoz, and M. Vilajeliu, 1995. Reflectance assessment of mite effects on apple trees. International Journal of Remote Sensing., 16: 2727-2733.

17. Thenkabail, P. S. 2003. Biophysical and yield information for precision farming from near-real-time and historical Landsat TM images. International Journal of Remote Sensing., 24 (14): 839-877.

18. Elvidge, C. D., Z. Chen, and D. P. Groeneveld, 1993. Detection of trace quantities of green vegetation in 1990 AVIRIS data. Remote Sens. of Environ., 44: 271-279.

19. Lyon, J. G., D. Yuan, R. S. Lunetta, and C. D. Elvidge, 1998. A change detection experiment using vegetation indices. Photogrammetric Engineering and Remote Sensing., 64 (2): 143-150.

20. Bauer, M. E., C. S. T. Daughtry and V. C. Vanderbilt, 1981. Spectralagronimic relationships of corn, soybean, and wheat canopies. Report SR-P1-04187. West Lafayette, IN: Laboratory for Applications of Remote Sensing, Purdue University., pp: 17.

21. Ustin, S. L., M. O. Smith, S. Jacquemoud, M. Verstraete, and Y. Govaerts, 1999. Geobotany: Vegetation Mapping for Earth Sciences. In A. N. Rencz (Ed.), Remote sensing for the earth sciences: Manual of remote sensing (pp: 189-247). New York: John Wiley and Sons.

22. Guyot, G., F. Baret, and S. Jacquemoud, 1992. Imaging Spectroscopy for Vegetation Studies. Imaging Spectroscopy: Fundamentals and Prospective Application., pp: 145-165.

23. Horler, D. N. H., M. Dockray and J. Barber, 1983. The red edge of plant leaf reflectance. International Journal of Remote Sensing., 4(2): 273-288.

24. Leprieur, C.E. 1989. Preliminary evaluation of AVIRIS airborne measurements for vegetation. Proc. 9th EARSeL Symp., Espoo, Finland, June 27-July., 1: 1-6.

25. Curran, P.J., W.R. Windham and H.L. Gholz, 1995. Exploring the relationship between reflectance red edge and chlorophyll concentration in slash pine leaves. Tree Physiol., 15: 203-206.

26. Baret, F., I. Champion, G. Guyot and A. Podaire, 1987. Monitoring wheat canopies with a high spectral resolution radiometer. Remote Sensing Environment., 22: 367-378.

27. Dawson, T. P. and P. J. Curran, 1998. A new Technique for Interpolating the Reflectance Red Edge Position. International Journal of Remote Sensing., 19: 2133-2139.

28. Belanger, M. J., J. R. Miller and M. G. Boyer, 1995. Comparative relationships between some red edge parameters and seasonal leaf chlorophyll concentrations. Can. J. Remote Sens., 21 (1): 16-21.

29. Munden, R., P. J. Curran, and J. A. Catt, 1994. The relationship between red edge and chlorophyll concentration in Broadbalk winter wheat experiment at Rothamsted. Int. J. Remote Sens., 15 (3): 705-709.

30. Danson, F. M. and S. E. Plummer, 1995. Red-edge response to forest leaf area index. International Journal of Remote Sensing., 16: 183-188. 
31. Filella, I. and J. Penuelas, 1994. The red edge position and shape as indicators of plant chlorophyll content, biomass and hydric status. International Journal of Remote Sensing, 15 (7): 1459-1470.

32. Niemann, K. O. 1995. Remote sensing of forest stand age using airborne spectrometer data. Photogramm. Eng. Remote Sens., 61 (9): 1119-1127.

33. Vane, G. and A. F. H. Goetz, 1988. Terrestrial imaging spectroscopy. Remote Sens. Environ., 24: 129.

34. Miller, J. R., J. Wu, M. G. Boyer, M. Belanger, and E. W. Hare, 1991. Season patterns in leaf reflectance red edge characteristics. Int. J. Remote Sens., 12 (7): 1509-1523.

35. Clevers, J. G. P. W., S. M. de Jong, , G. F. Epema, F. van der Meer, W. H. Bakker, A. K. Skidmore and K. H. Scholte, 2002. Derivation of the red edge index using the MERIS standard band setting. International Journal of Remote Sensing., 23: 3169-3184.

36. Dash, J. and P. J. Curran, 2003. MTCI: the MERIS terrestrial chlorophyll index. Proc. MERIS User Workshop, Frascati, Italy, (ESA SP-549, May 2004).

37. Guyot, G. and F. Baret, 1988. Utilisation de la Haute Resolution Spectrale Pour Suivre I'etat des Couverts Vegetaux. Proceedings, $4^{\text {th }}$ International Colloquium "Spectral Signatures of Objects in Remote Sensing", Aussois, 18-22 January 1988, Paris: ESA, ESA Publication SP-287., pp: 279-286.

38. Clevers, J. G. P. W. and R. Jongschaap, 2001. Imaging spectrometry for agricultural applications. In: F. D. van der Meer and S. M. De Jong (Editors), Imaging spectrometry: basic principles and prospective applications. Kluwer Academic, Dordrecht, The Netherlands., pp: 157-199.

39. Clevers, J. G. P. W., S. M. de Jong, , G. F. Epema, , F. van der Meer, , W. H. Bakker, A. K. Skidmore and E. A. Addink, 2001. MERIS and the red-edge position. JAG., 3 (4): 313-320.

40. Zarco-Tejada, P. J., J. C. Pushnik, S. Dobrowski, and S.L. Ustin, 2003. Steady-state chlorophyll $a$ fluorescence detection from canopy derivative reflectance and double-peak red-edge effects. Remote Sensing of Environment, 84: 283-294.

41. le Maire, G., C. Francois and E. Dufrene, 2004. Towards universal broad leaf chlorophyll indices using PROSPECT simulated database and hyperspectral reflectance measurements. Remote Sensing of Environment., 89: 1-28.

42. Broge, N. H. and E. Leblanc, 2000. Comparing prediction power and stability of broadband and hyperspectral vegetation indices for estimation of green leaf area index and canopy chlorophyll density. Remote Sens. of Environ., 76: 156-172.
43. Tsai, F. and W. Philpot, 1998. Derivative analysis of Hyperspectral Data. Remote Sensing of Environment., 66: 41-51.

44. Li, L. Ustin, S. L. and M. Lay, 2005. Application of AVIRIS data in detection of oil-induced vegetation stress and cover change at Jornada, New Mexico. Remote Sensing of Environment., 94: 1-16.

45. Denniss, A. and A. Bunn, 2001. SHAC UK's first SAR and hyperspectral airborne campaign. Geoinformatics, June., pp: 12-15.

46. HyVista, 2002. HyMap Hyperspectral Scanner, http//:www.hyvista.com/main.html, \{Accessed: 10 June 2002\}.

47. Kumar, L. and A. Skidmore, 1998. Use of Derivative Spectroscopy to Identify Regions of Differences between Some Australian Eucalypt Species. Proceedings $9^{\text {th }}$ Australasian Remote Sensing and Photogrammetry Conference, Sydney, New South Wales, CDROM.

48. Demetriades-Shah, T. H., M. D. Steven, and J. A Clark, 1990. High Derivatives Spectra in Remote Sensing. Remote Sens. of Environ., 33: 55-64.

49. Lacar, F. M., M. M. Lewis and I. T. Grierson, 2001. Use of Hyperspectral Reflectance for Discrimination between Grape Varieties. IEEE., pp: 2878-2880.

50. Smith, K. L., M. D. Steven, and J. J. Colls, 2004. Use of hyperspectral derivative ratios in the red-edge region to identify plant stress responses to gas leaks. Remote Sens. of Environ., 92: 207-217.

51. Imanishi, J., K. Sugimoto and Y. Morimoto, 2004. Detecting drought status and LAI of two Quercus species canopies using derivative spectra. Computers and Electronics in Agriculture., 43: 109-129.

52. Broge, N. H. and J. V. Mortensen, 2002. Deriving green crop area index and canopy chlorophyll density of winter wheat from spectral reflectance data. Remote Sensing of Environment., 81: 45-57.

53. Datt, B., M. Paterson, 2000. Vegetation-soil spectral mixture analysis. Proceedings of the IEEE International Geoscience and Remote Sensing., pp: 1936-1938.

54. Curran, P. J., J. L. Dungan and H. L. Gholz, 1990. Exploring the relationship between reflectance red edge and chlorophyll content in slash pine. Tree Physiology., 7: 33-48.

55. Mauser, W., and H. Bach, 1995. Imaging spectroscopy in hydrology and agriculturedetermination of model parameters. In: J. Hill, and J. Megier (Eds.), Imaging spectrometry-a tool for environmental observations (pp: 261-283). Dordrecht, The Netherlands: Kluwer Academic Publishing. 